\title{
Review of Oxidative Processes in Wine and Value of Reduction Potentials in Enology
}

\author{
John C. Danilewicz ${ }^{1 *}$
}

\begin{abstract}
The reduction potential of wines has been thought to indicate their level of oxidation or reduction, but how that relates to wine composition has remained vague. Reduction potentials are generated by redox couples, which are at equilibrium and both adsorbed on the measuring electrode, the magnitude of the potential for any couple being determined by the relative proportion of the oxidized and reduced component. However, redox couples associated with polyphenols, which are most likely to determine reduction potentials, are not at equilibrium in wine due to the instability of quinones. Reduction potentials are highly dependent on oxygen concentration and it is proposed that they are generated by the oxidation of ethanol coupled to the reduction of protons or of oxygen. While the so-called reduction potential is therefore of little value for wine, cyclic voltammetry has proved very useful in determining the reduction potential of wine constituents and estimating the concentration of the most readily reduced polyphenols. The reduction potentials of proposed redox couples involved in the reduction of oxygen and oxidation of polyphenols, ethanol, and sulfite are useful in determining the thermodynamic feasibility of possible interactions. The reaction of polyphenols with oxygen is mediated by iron, which redox cycles between them assisted by copper. Catechol-quinone and oxygen-hydrogen peroxide couples have similar reduction potentials. Consequently, the oxidation of catechols such as $(+)$-catechin cannot proceed to completion and is accelerated by substances that react with quinones, such as sulfite, which reduces them back to polyphenols. Sulfite, therefore, has multiple antioxidant activities. It accelerates oxygen consumption, prevents loss of polyphenols by regenerating them, and intercepts hydrogen peroxide, thus preventing ethanol oxidation.
\end{abstract}

Key words: reduction potentials, polyphenols, oxygen, sulfur dioxide, iron

\section{Reduction Potential of Wine}

The reduction potential of wines has been measured based on the premise that it indicates levels of oxidation or reduction, that is, their redox state. However, what that means at a molecular level in terms of wine composition has remained extremely vague. It might be imagined that a wine with a high reduction potential might be in an oxidized state in which reductants such as polyphenols, ascorbic acid, and sulfite are reacting. Conversely, a wine with a low reduction potential might be in a reduced state most likely to contain reduced sulfur compounds such as mercaptans. It might also be thought of as indicating different proportions of initial reduced substances and oxidized reaction products. However, both oxidized and reduced forms would need to be present and to react reversibly at the electrode before thermodynamically meaningful reduction potentials could be determined. Apart from metals, principally Fe, and possibly thiols, no such systems have been identified in wine.

When a polished bright platinum electrode is dipped in a wine, which has been stored in the absence of air, a low

\footnotetext{
${ }^{1} 44$ Sandwich Road, Ash, Canterbury, Kent CT3 2AF, United Kingdom. *Corresponding author (email: jdanilewicz@btconnect.com; tel.: 441304 $812530)$

Acknowledgment: The author thanks Paul Kilmartin for helpful comments on the initial draft of this review.

Manuscript submitted May 2011, revised Aug 2011, accepted Sept 2011

Copyright (C) 2012 by the American Society for Enology and Viticulture. All rights reserved.

doi: 10.5344/ajev.2011.11046
}

potential generally in the region of $\sim 200$ to $300 \mathrm{mV}$ relative to a standard hydrogen electrode can be observed. When oxygen is introduced this potential rises and is then shown to depend on oxygen concentration, increasing by 200 to $300 \mathrm{mV}$ at saturation (Joslyn 1949, Ribéreau-Gayon et al. 2000). Although electrodes are highly susceptible to poisoning by wine constituents, especially sulfur compounds, with special design and careful cleaning reproducible results are obtainable (Vivas et al. 1992, Ribéreau-Gayon et al. 2000). Since it was supposed that this potential indicated the state of oxidation or reduction of a wine, studies have examined the effect of different winery operations on the potential, which was shown to be very sensitive to oxygen concentration (Joslyn 1949, Ribéreau-Gayon et al. 2000). It has been proposed that reduction potential could predict likely reductive problems (Ribéreau-Gayon et al. 2000) and contribute to a wine's resistance to oxidation (Oliveira et al. 2002). Attempts have also been made to relate reduction potential and its derivative, $\mathrm{rH}$, to wine quality (Dikanović-Lučan and Palić 1992). However, there is now overwhelming evidence that this potential does not measure the redox state of a winelike system, and it is proposed that it arises largely from the oxidation of ethanol coupled to the reduction of protons or oxygen on the electrode surface, as these constituents are the most electroactive at platinum electrodes of those present in wine (Tomlinson and Kilmartin 1997, Kilmartin and Zou 2001, Kilmartin 2010).

To explain how this reduction potential is generated in wine, it is useful to consider in some detail how reduction potentials are generated with reference to the classic Fe(III)/ 
$\mathrm{Fe}(\mathrm{II})$ redox couple. The metal would be present as hexacoordinated complexes with water or other ligand, such as tartaric acid in wine, that would have a major effect on the reduction potential, but for simplicity they are represented as free ions in this initial discussion.

$\mathrm{Fe}(\mathrm{III})$ may gain an electron to be reduced to the ferrous state, while in the reverse direction Fe(II) can lose an electron to be oxidized to the ferric state (Equation 1). If a bright polished platinum electrode is introduced into a solution containing these two ions at $\mathrm{pH} 0$, they are adsorbed on the metal surface (Figure 1). Electrons move freely in the metal and some of highest energy can leave to reduce Fe(III), leading to a reduction in electronic energy in the metal and hence to a reduction in potential of the electrode relative to the solution. Conversely, Fe(II) may donate electrons to the metal, increasing potential. Since no net current flows through the system, the potential adjusts so that the rates of the two processes equalize, which will depend on the relative concentration of

$$
\begin{aligned}
& \mathrm{Fe}(\mathrm{III})+\mathrm{e}^{-} \rightleftharpoons \mathrm{Fe}(\mathrm{II}) \\
& 2 \mathrm{H}^{+}+2 \mathrm{e}^{-} \rightleftharpoons \mathrm{H}_{2} \\
& \mathrm{E}_{\mathrm{h}}=\mathrm{E}_{0}+\mathrm{RT} / \mathrm{nF} \ln ([\mathrm{Fe}(\mathrm{III})] /[\mathrm{Fe}(\mathrm{II})]) \\
& \mathrm{E}_{\mathrm{h}}(V)=\mathrm{E}_{0}+0.059 \log ([\mathrm{Fe}(\mathrm{III})] /[\mathrm{Fe}(\mathrm{II})]) \\
& \mathrm{E}_{\mathrm{h}}(V)=0.029 \log \left(\left[\mathrm{H}^{+}\right]^{2} /\left[\mathrm{H}_{2}\right]\right) \\
& \mathrm{E}_{\mathrm{h}}(V)=0.059 \log \left(\mathrm{H}^{+}\right)-0.029 \log \mathrm{p}
\end{aligned}
$$

$-0.029 \log \mathrm{p}=\mathrm{E}_{\mathrm{h}}-0.059 \log \left(\mathrm{H}^{+}\right)$

$r H=-\log p=E_{h} / 0.029+2 p H$

$$
\mathrm{K}_{1}{ }^{\prime}=\frac{\left[\mathrm{QH}^{-}\right]\left(\mathrm{H}^{+}\right)}{\left[\mathrm{QH}_{2}\right]} \quad \text { (9) } \quad \mathrm{K}_{2}{ }^{\prime}=\frac{\left[\mathrm{QH}^{2-}\right]\left(\mathrm{H}^{+}\right)}{\left[\mathrm{QH}^{-}\right]}
$$

$\mathrm{E}_{\mathrm{h}}(V)=\mathrm{E}_{0}-0.029 \log \left[\left(\mathrm{H}^{+}\right)^{2}+\mathrm{K}_{1}{ }^{\prime}\left(\mathrm{H}^{+}\right)+\mathrm{K}_{1}{ }^{\prime} \mathrm{K}_{2}{ }^{\prime}\right]$

$\mathrm{E}_{\mathrm{h}}(V)=\mathrm{E}_{0}-0.059 \mathrm{pH}$

$\mathrm{E}_{\mathrm{pH}^{1}}=\mathrm{E}_{0}{ }^{1}+0.059 \log \left(\mathrm{K}_{\mathrm{r}}+10^{-\mathrm{pH}}\right)$

$\mathrm{E}_{\mathrm{pH}^{2}}=\mathrm{E}_{0^{2}}+0.059 \log \frac{\left(\mathrm{K}_{1}{ }^{\prime} \cdot \mathrm{K}_{2}{ }^{\prime}+\mathrm{K}_{1}{ }^{\prime} \cdot 10^{-\mathrm{pH}}+10^{-2 \mathrm{pH}}\right)}{\mathrm{K}_{\mathrm{r}}+10^{-\mathrm{pH}}}$

Equations 1-14. the two ions. For instance, if the concentration of $\mathrm{Fe}(\mathrm{III})$ is increased, more electrons will leave the electrode and the potential will become more positive. The potential is therefore sensitive to the relative concentration of the oxidized and reduced components of the couple (Compton and Sanders 1996, Bard and Faulkner 2001).

To obtain the reduction potential, the potential of the above electrode is measured against a reference electrode, which by convention is the standard hydrogen electrode (SHE), the two systems connected by a salt bridge. This electrode is made of platinized platinum dipped in aqueous $\mathrm{HCl}$ of unit activity ( $\mathrm{pH} 0$ ) over which hydrogen is bubbled. Hydrogen ions and hydrogen at 1 atmosphere, which constitute the reference redox couple (Equation 2), are adsorbed on the metal surface. Hydrogen ions are reduced by accepting electrons from the metal while hydrogen is oxidized by donating them (Figure 1). The energy of the electrons in the metal, hence the potential of the electrode, equilibrates such that the rates of the opposing processes equalize as for the $\mathrm{Fe}$ system. Since the potential of the SHE is taken as zero, the difference in potential between the electrodes is then the reduction potential $\left(\mathrm{E}_{\mathrm{h}}\right)$ of the couple being studied. By using the SHE as a common standard, the reduction potential of different couples may be compared. However, the SHE is cumbersome to use and potentials are more conveniently measured against the standard calomel electrode (SCE) or silver/silver chloride electrode $(\mathrm{Ag} / \mathrm{AgCl} / 3 \mathrm{M} \mathrm{NaCl})$. Since these have potentials of $242 \mathrm{mV}$ and $207 \mathrm{mV}$ versus the SHE, respectively, these values then need to be added to the observed reading. In this review, all potentials are given against the SHE.

As described above, the observed potential will depend on the relative concentrations of the redox pair and this relationship is defined by the Nernst equation (Equation 3). $\mathrm{R}$ is the gas constant, $\mathrm{T}$ the absolute temperature, $\mathrm{F}$ is the Faraday constant, and $\mathrm{n}$ is the number of electrons transferred. At $25^{\circ} \mathrm{C}$ and when $\mathrm{n}=1$, the equation can be more conveniently written as Equation $4 . \mathrm{E}_{\mathrm{h}}$ is the observed potential

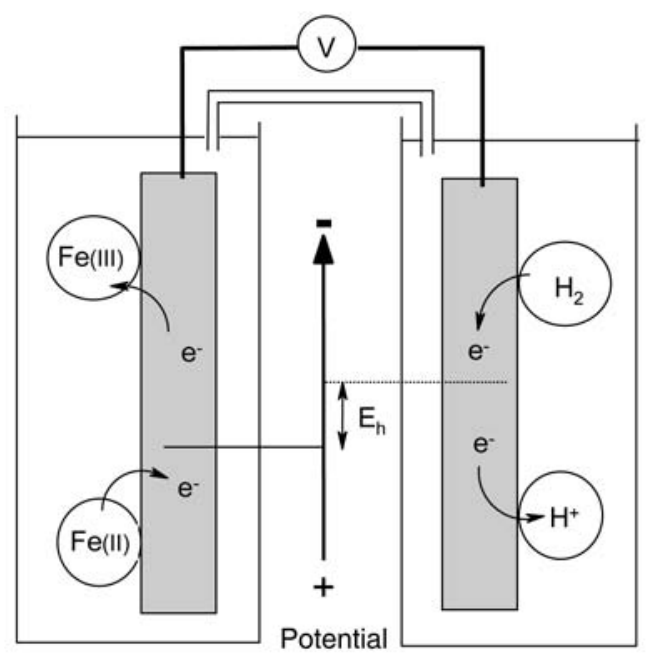

Figure 1 Schematic representation in which the reduction potential $\left(E_{h}\right)$ of the $\mathrm{Fe}(\mathrm{III}) / \mathrm{Fe}(\mathrm{II})$ couple is measured against a standard hydrogen electrode. 
with reference to the hydrogen standard. $\mathrm{E}_{0}$ is the formal potential, which is the potential when oxidant and reductant are at equal concentration, and $\mathrm{H}^{+}$is at unit activity ( $\mathrm{pH} 0$ ). At low concentration $\mathrm{E}_{0}$ approximates to $\mathrm{E}^{0}$, the standard reduction potential, when all components of the system are at unit activity.

The change in free energy $(\Delta \mathrm{G})$ associated with a redox process is given by the relationship $-\Delta \mathrm{G}=\mathrm{nF} \Delta \mathrm{E}_{0}$, which determines the thermodynamic feasibility and direction of the reaction, with $\Delta \mathrm{E}$ the difference in reduction potential between the reacting couples. The more positive $\mathrm{E}_{0}$, the greater the oxidizing power of an oxidant; the lower $\mathrm{E}_{0}$, the greater the reducing power of the reductant (Buettner 1993). Reduction potentials, therefore, allow the ranking of oxidants and reductants as to their ability to accept or donate electrons, respectively, and hence how they may interact and also provide a means of determining the relative concentrations of oxidant and reductant in a system. Consequently, it might be assumed that the observed potential of a wine, which depends on degree of exposure to oxygen, indicates the relative concentration of oxidized and reduced species and hence the redox state of that wine.

However, in order for a reduction potential to be generated in a classic sense, both oxidant and reductant of a redox couple must be present and be able to undergo electron transfer at the electrode surface. The main oxidizable substances in wine are polyphenols, such as (+)-catechin, the catechol system of which is oxidized to the quinone (Scheme 1). By convention this reaction is drawn as a reduction to specify reduction potentials; however, to facilitate discussion in this review, redox couples involving polyphenols will be referred to by the name of the polyphenol.

A problem with this compound class is the instability of the ortho-quinone, which prevents the attainment of equilibrium conditions in wine. This difficulty is well illustrated by the first determination of the reduction potential of catechol (1,2-benzenediol) itself. It proved possible to prepare the quinone by oxidizing catechol with silver oxide in dry ether. Rapid dissolution in $0.1 \mathrm{~N} \mathrm{HCl}$ and reduction by titration with $\mathrm{TiCl}_{3}$ in a potentiometric cell fitted with a platinum and hydrogen reference electrode gave $\mathrm{E}_{0}=782 \mathrm{mV}$. Electrode equilibrium was very rapidly attained so that the titration could be completed in a few minutes. The standard potential was then derived directly from the midpoint of the titration curve when the concentration of catechol and quinone would be equal, according to the Nernst equation (Conant and Fieser 1924).

Subsequently, a more elaborate approach was adopted to compensate for any possible quinone decomposition (Ball and Chen 1933). Solutions of catechol and the oxidant $\mathrm{Ce}\left(\mathrm{SO}_{4}\right)_{2}$ of varying concentration in $0.1 \mathrm{M}$ acetate buffer $\mathrm{pH} 4.388$ and

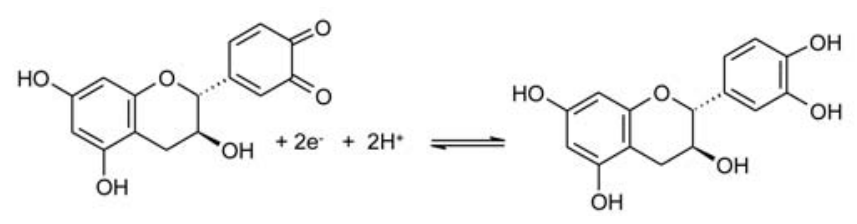

Scheme 1 (+)-Catechin redox couple. varying flow rates were mixed just before passage through an elongated cell. The cell was fitted with four platinum electrodes spaced along its length so that any change in potential (versus a SCE) as the mixture passed successive electrodes along the cell indicated loss of quinone. From the known flow rate, it was then possible to determine the rate of decomposition and hence the potential at the instant of mixing. $\mathrm{E}_{0}$, when the concentration of catechol and quinone was equal at $\mathrm{pH}$ 0 , was then found to be $793 \mathrm{mV}$. The stability of the quinone decreased sharply with increasing $\mathrm{pH}$, with $30 \mathrm{~min}, 8 \mathrm{~min}$,

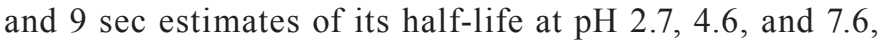
respectively. The presence of reactive nucleophiles in wine would no doubt further reduce stability.

The quinone of caffeic acid was obtained by oxidation with chloranil in tetrahydrofuran-ether at $-60^{\circ} \mathrm{C}$ to $-70^{\circ} \mathrm{C}$, and although the crystalline compound could be stored at $-80^{\circ} \mathrm{C}$, it was unstable at $-20^{\circ} \mathrm{C}$ (Davies 1976). Quinones have been observed by HPLC when (+)-catechin and (-)-epicatechin were rapidly oxidized with polyphenoloxidase, but these products were rapidly lost, that of (-)-epicatechin most rapidly (Richard-Forget et al. 1992). The quinone is undoubtedly formed when $(+)$-catechin is oxidized in winelike conditions, as it can be trapped with benzenesulfinic acid to form the sulfone adduct. The half-life for the reaction of oxygen can vary from 4 to 45 days in wine depending on whether it is red or white and the $\mathrm{Fe}$ and $\mathrm{Cu}$ content (Danilewicz and Wallbridge 2010). Quinone decomposition is so much faster than the rate of polyphenol oxidation that accumulation of quinones, let alone the attainment of redox equilibrium, is not possible. In order for reduction potential to reflect the redox state of wine, oxidized derivatives of polyphenols, presumably quinones, have to be present in varying amounts depending on the extent of oxygen exposure. One difficulty, therefore, in understanding wine reduction potentials is that redox couples, which are most likely to contribute to such potentials, are absent. An indication that all is not well in the interpretation of wine reduction potentials is that if the $(+)$-catechin redox couple were to adopt a potential of $560 \mathrm{mV}$ at a platinum electrode, $\sim 25 \%$ would have to be oxidized to the quinone within minutes on saturation of a wine with air, which is clearly not so.

It became apparent that polyphenols do not contribute to reduction potential when it was considered that red and white wines behaved similarly with respect to this potential in their response to oxygen exposure, despite the much greater polyphenol concentration in the former (Vivas et al. 1993, Kilmartin and Zou 2001). Removal of polyphenols from red and white wine with charcoal also has only a minor effect on reduction potential (Vivas et al. 1992). It is also evident that quinones are not present, as sulfite, which quickly reduces them back to catechols (Makhotkina and Kilmartin 2009, Danilewicz and Wallbridge 2010), has little effect on the observed potential of red wine (Vivas et al. 1993). In addition, the reduction potential of model wine that does not contain polyphenols behaves somewhat similarly to wine on exposure to oxygen and the addition of (+)-catechin or gallic acid produces little effect (Kilmartin and Zou 2001). The evidence is, therefore, overwhelming that polyphenols, the 
most oxidizable constituents of wine, do not contribute to the so-called reduction potential.

Wine reacts very slowly with oxygen, taking weeks and even months for it to be removed, depending on $\mathrm{Fe}$ and $\mathrm{Cu}$ concentration and the presence of substances, including sulfite, that react with quinones (Danilewicz and Wallbridge 2010). Saturation of wine with oxygen results in a prompt increase in the observed potential, which slowly recovers over time as the oxygen reacts (Ribéreau-Gayon et al. 2000). Evidently oxygen is reacting slowly with polyphenols, but when the wine is flushed with an inert gas, the reduction potential drops immediately. Clearly, as far as this reduction potential is concerned, oxygen is interacting with a very responsive system, which cannot involve polyphenol oxidation.

It transpires that this so-called reduction potential is not a reduction potential at all but a mixed potential, which is caused by the oxidation of ethanol on the platinum electrode (Tomlinson and Kilmartin 1997, Kilmartin and Zou 2001). It is proposed that in the absence of oxygen, when potential is at a minimum value, the oxidation is coupled with the reduction of hydrogen ions (Figure 2A). When oxygen, which is a much stronger oxidant, is introduced the rate of oxidation and observed potential rises (Figure 2B). The generated potential is that at which oxidation and reduction occur at the same rate, since there is no net current flow and it will depend on $\mathrm{O}_{2}$ concentration.

In conclusion, the measurement of reduction potential is a complicated way of obtaining a general indication as to how much oxygen is present in a wine. It is far simpler to obtain accurate values using a Clark electrode (Danilewicz and Wallbridge 2010). The measured reduction potential must depend on how a wine is handled immediately before measurement with respect to oxygen ingress, and it cannot indicate how much oxygen a wine has reacted with previously or its capacity or readiness to do so in the future. Thiols and Fe may oxidize relatively quickly on exposure to oxygen, but the overall redox status of wine might only be surmised by knowing how much oxygen a wine has been exposed to over what time, how much has reacted, and how much remains. At present there seems to be no simple indicator of the so-called redox status, which in any case requires a much clearer definition.

As will be discussed in more detail below, the reduction potential of redox systems in which the reduced component can protonate is $\mathrm{pH}$ dependent. Consequently, in order to refer

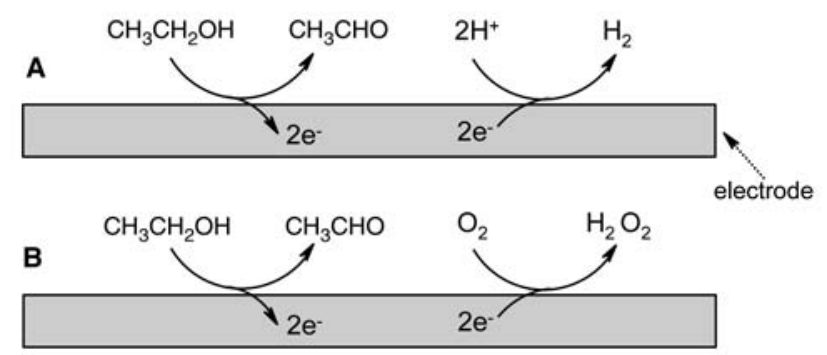

Figure 2 Oxidation of ethanol coupled to reduction of hydrogen ions (A) or oxygen (B), which produces the so-called reduction potential in wine. to reduction potential without specifying $\mathrm{pH}$, and to compare systems with different $\mathrm{pHs}$, Clark introduced the concept of $\mathrm{rH}$, which he later regretted and called an "unmitigated nuisance," as it adds a further level of complication to an already complicated situation (Clark 1960). It is derived by imagining that the reduction potential of a wine is produced at a hydrogen electrode at the $\mathrm{pH}$ of the wine. The reduction potential of such a system is given by the Nernst equation (Equation 5 ), as $\mathrm{E}_{0}$ for the SHE is set at zero. $\left[\mathrm{H}_{2}\right]$ is the hydrogen concentration, which is taken as its partial pressure (p), giving Equation 6. Rearrangement then gives Equation 7, in which $\mathrm{rH}$ is defined as the negative logarithm of the hydrogen partial pressure at an imaginary hydrogen electrode at the $\mathrm{pH}$ of the wine, $\mathrm{E}_{\mathrm{h}}$ being the measured wine reduction potential (Equation 8) (Kilmartin and Zou 2001). rH values have been used to compare wines, but since they are derived directly from the measured reduction potential they are of no greater value in defining redox state.

\section{Cyclic Voltammetry}

While the direct measurement of the reduction potential of wine using platinum electrodes has resulted in misunderstanding and confusion, cyclic voltammetry using glassy carbon electrodes is proving very useful (Kilmartin et al. 2001). When a platinum electrode is placed in aqueous ethanol and the potential is progressively made more positive, an anodic current is produced by the oxidation of ethanol to acetaldehyde and then water to oxygen. These processes are not observed on a glassy carbon electrode, which on the other hand readily allows the oxidation of polyphenols to occur and the reduction of certain oxidation products (Kilmartin 2001, Kilmartin and Zou 2001). Therefore, when the potential of such electrodes is swept to more positive values, generally at a rate of $100 \mathrm{mV} \mathrm{s}^{-1}$, a point is reached when electrons are withdrawn from the polyphenol, generating an anodic current, which increases to a peak $\left(\mathrm{E}_{\mathrm{pa}}\right)$ (Figure 3), when most of the polyphenol in the vicinity of the electrode is oxidized to the quinone. Reversing the potential sweep, a reverse current

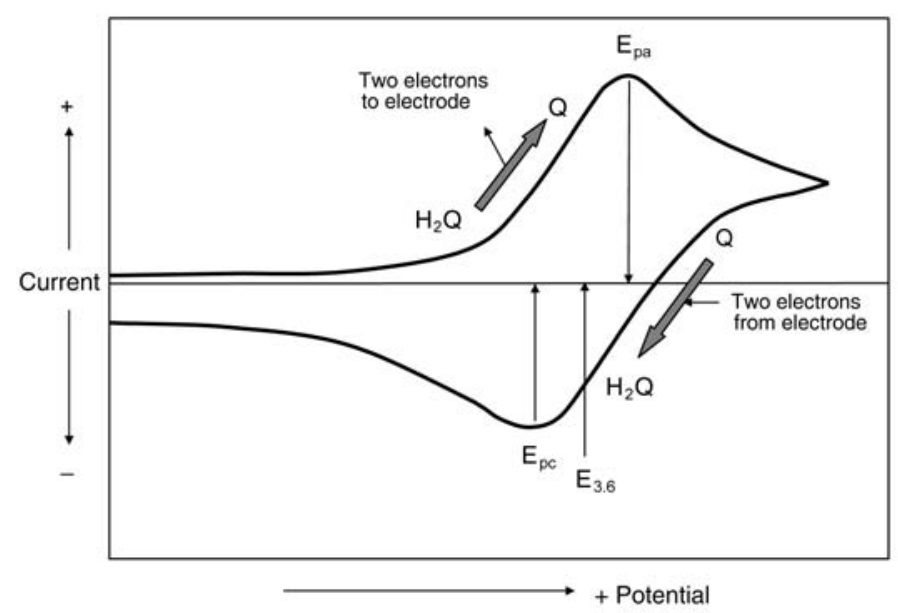

Figure 3 Idealized voltammogram representing the forward oxidation of a catechol $\left(\mathrm{H}_{2} \mathrm{Q}\right)$ and reverse reduction of the resulting quinone $(\mathrm{Q})$ in model wine at $\mathrm{pH} 3.6$. 
is produced as the quinone is reduced back to the catechol, producing a cathodic peak potential, $\mathrm{E}_{\mathrm{pc}}$, when most of the quinone is reduced. The polyphenol and quinone are supplied and removed from the electrode under diffusion control, which determines the current peaks obtained and the shape of the voltammograms. The potential midway between $\mathrm{E}_{\mathrm{pa}}$ and $\mathrm{E}_{\mathrm{pc}}$ is taken as the formal potential, $\mathrm{E}_{\mathrm{pH}}$, at the $\mathrm{pH}$ of the system. At that point the concentration of the polyphenol and quinone are assumed to be equal at the electrode.

The voltammogram shown in Figure 3 represents the ideal, when the quinone is sufficiently stable and symmetrical curves are obtained. (+)-Catechin and caffeic acid approach this ideal pattern, but when the quinone is much less stable, such as with gallic acid, the reverse cathodic wave may be greatly suppressed. In this situation it is possible to estimate $\mathrm{E}_{\mathrm{pH}}$ by taking the value midway between the half-peak potential $\left(\mathrm{E}_{\mathrm{p} / 2}\right)$ and $\mathrm{E}_{\mathrm{pa}}$ (Kilmartin 2001). By this method the reduction potentials, $\mathrm{E}_{3.6}$, of a number of polyphenols have been determined under winelike conditions (Kilmartin 2001) (Table 1). The corresponding formal potentials, $E_{0}$, are calculated from these results and compared with values calculated from $\mathrm{E}_{6.2}$ values obtained from polarographic half-wave potentials (Horner and Geyer 1965). Also included are formal potentials determined earlier by potentiometric titration as well as estimates of half-lives of some quinones obtained as described above (Ball and Chen 1933). The quinones of pyrogallol and gallic acid are extremely unstable, as also indicated by their voltammograms.

As will be discussed below, nucleophiles which react with quinones accelerate polyphenol oxidation. In the case of $(+)$-catechin, sulfite regenerates it by reducing the quinone while benzenesulfinic acid adds to the quinone in a Michael fashion to produce the sulfone adduct (Danilewicz and Wallbridge 2010). The reaction of sulfite is indeed very rapid as it markedly potentiates the anodic current in the cyclic voltam-

Table 1 Two-electron reduction potentials of quinone/catechol redox couples.

\begin{tabular}{lccccc}
\hline & $\begin{array}{c}\mathbf{E}_{3.6} \mathbf{m V} \mathbf{V}^{\mathrm{a}} \\
\mathbf{0 . 0 5} \mathbf{~ m M}\end{array}$ & $\mathbf{E}_{\mathbf{0}} \mathbf{m V}^{\mathrm{b}}$ & $\mathbf{E}_{\mathbf{0}} \mathbf{m V}^{\mathrm{c}}$ & $\mathbf{E}_{\mathbf{0}} \mathbf{m V}^{\mathrm{d}}$ & $\begin{array}{c}\text { Quinone } \\
\mathbf{t}_{1 / 2}{ }^{\mathrm{e}}\end{array}$ \\
\hline (+)-Catechin & 577 & 789 & & & \\
(-)-Epicatechin & 568 & 780 & & & \\
Caffeic acid & 604 & 816 & 793 & & \\
Gallic acid & 582 & 794 & & 799 & $0.24 \mathrm{sec}$ \\
Quercetin & 567 & 779 & 744 & & \\
4-Methylcatechol & $541^{\dagger}$ & & 753 & & \\
1,2-Benzenediol & $582^{\dagger}$ & & 795 & 793 & $13.6 \mathrm{~min}$ \\
Protocatechuic acid & & & & 883 & $2.1 \mathrm{~min}$ \\
Pyrogallol & $468^{\dagger}$ & & 680 & 713 & $0.24 \mathrm{sec}$ \\
\hline
\end{tabular}

aObtained by voltammetry in model wine $\mathrm{pH} 3.6$, adding $207 \mathrm{mV}$ to give values vs. SHE (Kilmartin et al. 2001).

'Obtained by adding $212 \mathrm{mV}$ to the value obtained at $\mathrm{pH} 3.6$ to give values at $\mathrm{pH} 0$ according to equation $\mathrm{E}_{\mathrm{pH}}=\mathrm{E}_{0}-0.059 \mathrm{pH}$.

'Standard reduction potential calculated from values obtained in phosphate buffer pH 6.72 by polarography (Horner and Geyer 1965). 'Obtained by potentiometric titration with $\mathrm{Ce}\left(\mathrm{SO}_{4}\right)_{2}$ (Ball and Chen 1933). e Estimated half-life of quinone at $\mathrm{pH} 1.3,30^{\circ} \mathrm{C}$ (Ball and Chen 1933). ${ }^{\dagger}$ Calculated by the author from $\mathrm{E}_{0}$. mogram of (+)-catechin and markedly decreases or abolishes the cathodic current, indicating that the quinone has been removed (Makhotkina and Kilmartin 2009). With catechol, benzenesulfinic acid displaces the anodic peak to higher potential and also abolishes the cathodic peak (Nematollahi and Rahchamani 2002). It is noted that $\mathrm{E}_{0}$ for the sulfone adduct should be some $80 \mathrm{mV}$ higher than that of catechol because of the electron-withdrawing effect of the substituent (Horner and Geyer 1965).

Diluted wines also display cyclic voltammograms. The anodic peak of white wines generally occurs between 645 and $703 \mathrm{mV}$, with caffeic acid derivatives as the main contributors. The anodic peaks of red wines occur at slightly lower potential $(\sim 640 \mathrm{mV})$, in line with their greater flavanol content with an additional peak at $\sim 840 \mathrm{mV}$, thought partly due to pigments and greater concentration of weakly reducing phenols (Makhotkina and Kilmartin 2009, Kilmartin et al. 2002). Each wine constituent would contribute to the anodic current according to their concentration, and it has been proposed that the current observed to $500 \mathrm{mV}$ against an $\mathrm{Ag} / \mathrm{AgCl}$ electrode ( $707 \mathrm{mV}$ versus SHE) is a more selective indication of the concentration of the more reducible polyphenols, such as catechols and pyrogallol derivatives, than the Folin-Ciocalteu test (Kilmartin et al. 2002). The method has been modified to remove sulfite interference by adding a small amount of acetaldehyde (Makhotkina and Kilmartin 2010). Cyclic voltammetry has also been used to study wines of different origin and ages and to determine the effect of accelerated aging on adding $\mathrm{O}_{2}$ and $\mathrm{SO}_{2}$ as well as increasing pH (Rodrigues et al. 2007, Martins et al. 2008).

\section{Redox Systems in Wine}

Although it is argued that the measurement of wine reduction potentials is of very limited value, if any at all, consideration of the reduction potential of individual wine constituents can provide useful insights into the mechanism of oxidative processes. A well-known example is the ability of ascorbic acid to be oxidized in preference to catechols, such as (+)-catechin, as it has a much lower reduction potential. However, it is an oversimplification to view the compound as a simple antioxidant, as hydrogen peroxide is produced and the product, dehydroascorbic acid, is unstable, decomposing to many reactive substances including L-xylosone (Scheme 2). This aldehyde has been shown to react with $(+)$-catechin to give adducts, which yield yellow xanthylium cation pigments under winelike conditions. The presence of sulfite is therefore

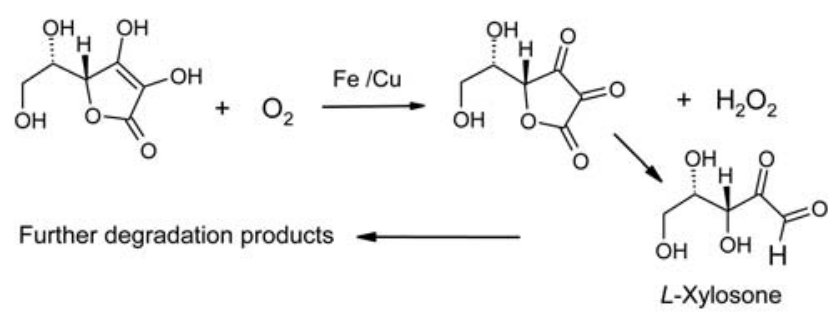

Scheme 2 Oxidation of ascorbic acid and degradation of dehydroascorbic acid. 
also required to prevent the oxidative changes induced by ascorbic acid by removing the hydrogen peroxide and the various carbonyl derivatives that are produced (Barril et al. 2009, Bradshaw et al. 2011).

As discussed above, in redox systems in which the reduced component can protonate, as in the quinone/catechol couple (Scheme 3A), the free energy of protonation needs to be taken into account. The observed reduction potential $\left(\mathrm{E}_{\mathrm{pH}}\right)$ will therefore depend on $\mathrm{pH}, \mathrm{K}_{1}$, and $\mathrm{K}_{2}$ or omitting activity coefficients $\mathrm{K}_{1}$ ' and $\mathrm{K}_{2}$ ' (Equations 9 and 10), as these parameters determine the extent of protonation of the various anions that are produced. The relationship between $\mathrm{E}_{\mathrm{pH}}$ and $\mathrm{E}_{0}$ is shown in Equation 11, which simplifies to Equation 12 when $\mathrm{pH}$ is much lower than $\mathrm{pK}_{1}$ and $\mathrm{pK}_{2}$ (Ball and Chen 1933, Clark 1960). The two-electron reduction potential $\left(\mathrm{E}_{3.6}\right)$ for the $(+)$-catechin couple is $577 \mathrm{mV}$. Therefore, the formal reduction potential $\mathrm{E}_{0}$ will be $789 \mathrm{mV}$, since $\mathrm{E}_{\mathrm{pH}}$ falls by 59 $\mathrm{mV}$ per $\mathrm{pH}$ unit increase at $25^{\circ} \mathrm{C}$. Using the flow technique described earlier, the $\mathrm{pH}$ dependence of $\mathrm{E}_{\mathrm{pH}}$ for catechol agreed exactly with the theoretical value of $60.1 \mathrm{mV} / \mathrm{pH}$ unit at $30^{\circ} \mathrm{C}$ (Ball and Chen 1933).

The redox reaction for the $\mathrm{O}_{2} / \mathrm{H}_{2} \mathrm{O}_{2}$ couple may be represented in a similar manner (Scheme $3 \mathrm{~B}$ ). $\mathrm{E}_{7}$ for the twoelectron reduction is $365 \mathrm{mV}$ (Meisel and Czapski 1975, Wood 1988), and since $\mathrm{E}_{\mathrm{pH}}$ will have the same $\mathrm{pH}$ dependence as (+)-catechin, $\mathrm{E}_{3.6}$ and $\mathrm{E}_{0}$ will be $565 \mathrm{mV}$ and $778 \mathrm{mV}$, respectively. Therefore, the $\mathrm{O}_{2} / \mathrm{H}_{2} \mathrm{O}_{2}$ and (+)-catechin couples have essentially identical reduction potentials in the $\mathrm{pH}$ range 0 to $\sim 9$ (see also later discussion).

When $(+)$-catechin reacts with oxygen, the difference in reduction potential $(\Delta \mathrm{E})$ between the two redox couples will therefore be close to zero (Scheme 4). $\Delta \mathrm{E}$ is the sum of the two potentials with the sign for the potential of the couple which is oxidized reversed. A positive $\Delta \mathrm{E}$ value indicates that the reaction would proceed to the right and a negative value to the left. Since $\Delta \mathrm{E}=0.029 \log \mathrm{K}$ and the change in free energy, $-\Delta \mathrm{G}=\mathrm{nF} \Delta \mathrm{E}$, there is no driving force for the reaction

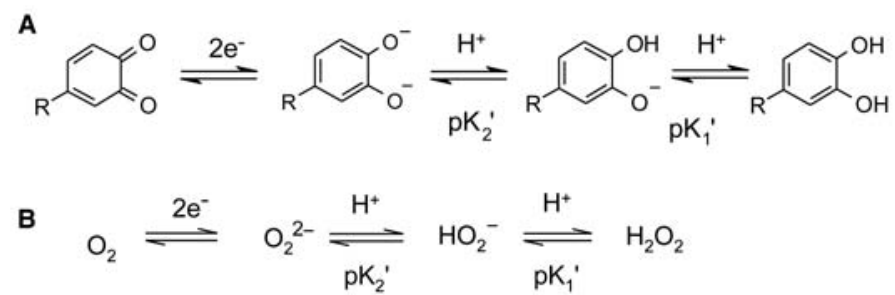

Scheme 3 Quinone/polyphenol and $\mathrm{O}_{2} / \mathrm{H}_{2} \mathrm{O}_{2}$ redox couples and protonation equilibria.

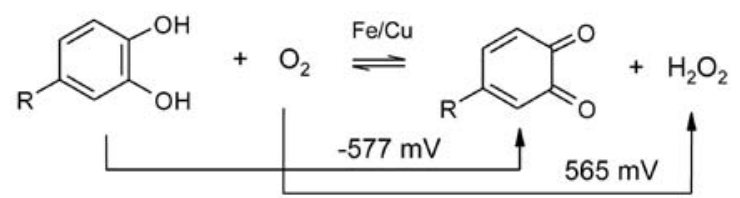

Scheme 4 Reaction of (+)-catechin with oxygen. to occur $(\Delta \mathrm{G}=0)$ and at best it should not proceed beyond half-way, as the equilibrium constant $\mathrm{K}=1$, even up to $\mathrm{pH} \sim 9$. Although the reduction potential of the reductant couple may fall with increasing $\mathrm{pH}$, its reducing power may not change, as the reduction potential of the oxidant couple may also fall to a similar extent. The thermodynamics of the reaction is determined by the difference in reduction potential $(\Delta \mathrm{E})$. The reaction of $(+)$-catechin with oxygen is indeed extremely slow in wine conditions. However, the observation that its oxidation is markedly accelerated by sulfite and by increasing $\mathrm{pH}$, although thermodynamically no more favored, reveals an important aspect of the mechanism of autoxidation of polyphenols.

When a solution of $(+)$-catechin in model wine containing catalytic amounts of $\mathrm{Fe}$ and $\mathrm{Cu}$ is saturated with oxygen, a small amount of oxygen is taken up initially to oxidize Fe(II), but after that very little further reaction is evident over three weeks (Danilewicz 2011). In contrast, when sulfite is added a relatively rapid oxygen uptake is observed. As discussed below, sulfite autoxidation is a metal-catalyzed radical chain reaction, which is prevented by radical scavengers such as polyphenols (Danilewicz 2007). Consequently, despite the long-held belief to the contrary, sulfite does not react with oxygen directly but with the hydrogen peroxide and quinone that are produced (Scheme 4). The quinone is reduced back to the catechol, such that in the case of $(+)$-catechin its concentration does not appear to decrease as it is oxidized. It was therefore proposed that oxidation involves an equilibrium, which is driven forward by removal of the quinone. Support for this proposal came from the finding that other nucleophiles such as benzenesufinic acid and azide, which are known to react with quinones, similarly promote $(+)$-catechin oxidation. Furthermore, it was concluded that the increase in rate of polyphenol oxidation with increasing $\mathrm{pH}$ is due to the increased rate of removal of the quinone because of its increasing instability, as discussed above. Overall, therefore, it is proposed that the oxidation of polyphenols, such as $(+)$-catechin, caffeic acid, and gallic acid and its esters, with redox couples of similar reduction potential to that of the $\mathrm{O}_{2} / \mathrm{H}_{2} \mathrm{O}_{2}$ system, will be determined, not only by the catalytic action of $\mathrm{Fe}$ and $\mathrm{Cu}$, but also by substances that can react with their quinones (Danilewicz 2011).

There is now good evidence that the oxidation of polyphenols is mediated by the catalytic action of $\mathrm{Fe}$, which is further enhanced by $\mathrm{Cu}$ (Scheme 5). The omission of these metals from model wines prevents polyphenol oxidation and their removal from wine can slow and even stop oxygen consumption. It is proposed that the oxidative process is initiated by the reaction of $\mathrm{Fe}(\mathrm{II})$ with oxygen, which in a stepwise manner would produce hydroperoxyl radicals and then hydrogen peroxide. Catechols are then proposed to coordinate with the

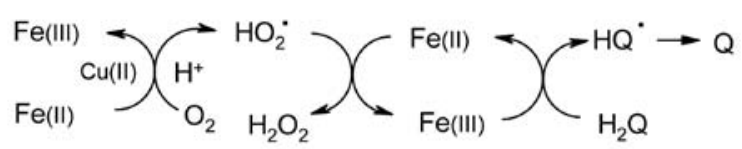

Scheme 5 A proposed mechanism for polyphenol oxidation: initiation by the oxidation of $\mathrm{Fe}(\mathrm{II})$. 
$\mathrm{Fe}$ (III) that is produced, electron transfer within the complex returning $\mathrm{Fe}$ to the ferrous state to continue the redox cycle, while the catechol is oxidized stepwise to the semiquinone radical and quinone (Danilewicz 2011).

$\mathrm{Fe}(\mathrm{III})$ and $\mathrm{Fe}(\mathrm{II})$ are coordinated to tartaric acid in wine conditions. $\mathrm{Fe}$ (II) forms a monomeric complex but $\mathrm{Fe}(\mathrm{III})$ binds much more strongly, forming dimeric and trimeric complexes in the $\mathrm{pH}$ range of wine (Timberlake 1964, Yokoi et al. 1994). In the presence of just three equivalents of tartaric acid, the reduction potential of the couple is reduced to $\sim 350 \mathrm{mV}$ at pH 3.6 (Green and Parkins 1961). The potential is probably close to that value in wine conditions, bringing it below that of the $\mathrm{O}_{2} / \mathrm{H}_{2} \mathrm{O}_{2}$ couple $(565 \mathrm{mV})$, thus making the oxidation of $\mathrm{Fe}$ (II) thermodynamically favorable. With the assistance of $\mathrm{Cu}$, the reaction proceeds rapidly in wine conditions. Although tartaric acid makes $\mathrm{Fe}(\mathrm{II})$ a stronger reductant, conversely it makes $\mathrm{Fe}(\mathrm{III})$ a weaker oxidant. The reduction potential of $\mathrm{Fe}(\mathrm{III}) / \mathrm{Fe}$ (II) couple would be below that of the catechol couple, so making its oxidation by Fe(III) thermodynamically disfavored, which presumably contributes to the slowness of the reaction, unless sulfite or other nucleophile such as glutathione is present to displace the unfavorable equilibrium and draw the reaction forward (Danilewicz 2011).

It does appear that Fe redox cycles between oxygen and the polyphenol, producing quinone and hydrogen peroxide (Scheme 5). The quinone may be trapped with benzenesulfinic acid (Danilewicz and Wallbridge 2010) and the Fenton reaction involving hydrogen peroxide occurs in wine conditions (Elias and Waterhouse 2010). Furthermore, two equivalents of $\mathrm{SO}_{2}$ react for each of oxygen that is consumed, one reacting with the quinone and the other with the hydrogen peroxide.

Further mechanistic insights can be obtained by considering each step of the redox process. Considering the $(+)$-catechin couple first, the two-electron reduction potential at $\mathrm{pH}$ $3.6\left(\mathrm{E}_{3.6}=577 \mathrm{mV}\right)$ is the mean of the first $\left(\mathrm{E}_{3.6}{ }^{1}\right)$ and second $\left(\mathrm{E}_{3.6}{ }^{2}\right)$ reduction potentials (Scheme 6). Both potentials are $\mathrm{pH}$ dependent, as shown by Equations 13 and 14, where $\mathrm{pKr}=$ 4.6, the dissociation constant of the semiquinone radical and $\mathrm{K}_{1}, \mathrm{~K}_{2}$, are as previously defined.

The second reduction potential $\left(\mathrm{E}_{3}{ }^{2}\right)$ has been determined by pulse radiolysis at $\mathrm{pH} 3$ and found to be $1.04 \mathrm{~V}$ (Jovanovic et al. 1996), from which $\mathrm{E}_{3.6}{ }^{2}=1.00 \mathrm{~V}$ is obtained. Given the two-electron reduction potential, $\mathrm{E}_{3.6}{ }^{1}$ is then calculated as

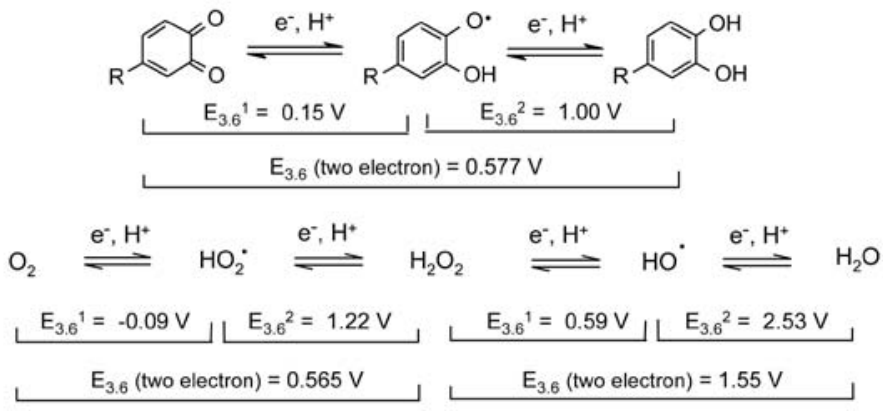

Scheme 6 Reduction potentials for the (+)-catechin and $\mathrm{O}_{2} / \mathrm{H}_{2} \mathrm{O}$ redox systems at pH 3.6.
$154 \mathrm{mV}$ and using Equations 13 and 14, the $\mathrm{pH}$ dependence of first, second, and two-electron reduction potentials are plotted (Figure 4). The reduction potentials are lowered by $59 \mathrm{mV}$ per $\mathrm{pH}$ unit up to $\mathrm{pH} \sim 4$, but the slopes of the first and second reduction potentials change at $\mathrm{pH} \sim 4.5$, as the $\mathrm{pH}$ approaches the value for the dissociation constant of the semiquinone. $\mathrm{E}_{\mathrm{pH}}{ }^{1}$ remains constant beyond $\mathrm{pH} \sim 5.5$, as the semiquinone is then almost fully deprotonated. As discussed earlier, the two-electron reduction potential is reduced linearly by $59 \mathrm{mV}$ per $\mathrm{pH}$ unit up to $\mathrm{pH} 9$.

The relationship between $\mathrm{pH}$ and first, second, and twoelectron reduction potentials for the $\mathrm{O}_{2} / \mathrm{H}_{2} \mathrm{O}_{2}$ redox couple are similarly plotted (Figure 4), using reported $\mathrm{pK}_{\mathrm{r}}, \mathrm{E}_{7}{ }^{1}, \mathrm{E}_{7}{ }^{2}$ values of $4.8,-160 \mathrm{mV}$ and $890 \mathrm{mV}$. The $\mathrm{E}_{7}{ }^{1}$ value of $-160 \mathrm{mV}$ is taken for oxygen at $1 \mathrm{M}$ concentration, rather than at 1 atmosphere $(-330 \mathrm{mV})$, which would be more usually taken as the standard state. This is to allow direct comparison with other redox couples (Meisel and Czapski 1975, Wood 1988). The curves show the same pattern as those for the $(+)$-catechin couple, and values for the two-electron reduction potentials superimpose almost exactly those for $(+)$-catechin, as previously discussed.

From the single-electron reduction potentials, it can be seen that the disproportionation of the hydroperoxyl radical would be thermodynamically highly favored $(\Delta \mathrm{E}=1.31 \mathrm{~V})$ (Scheme 7). However, catechols are present in much higher concentrations, and although less favored, they may intercept hydroperoxyl radicals $\left(\Delta \mathrm{E}_{3.6}=0.22 \mathrm{~V}\right)$. These radicals are also capable of both oxidizing $\mathrm{Fe}(\mathrm{II})\left(\Delta \mathrm{E}_{3.6} \sim 0.87 \mathrm{~V}\right)$ and reducing $\mathrm{Fe}(\mathrm{III})\left(\Delta \mathrm{E}_{3.6} \sim 0.44 \mathrm{~V}\right)$, assuming that the reduction potential of the $\mathrm{Fe}(\mathrm{III}) / \mathrm{Fe}$ (II) couple is $\sim 350 \mathrm{mV}$ (Scheme 7).

The reaction of polyphenols with oxygen in winelike conditions results in the oxidation of ethanol to produce acetaldehyde (Wildenradt and Singleton 1974). This transformation occurs by way of the Fenton reaction, which is initiated by the reduction of hydrogen peroxide by $\mathrm{Fe}(\mathrm{II})$ to produce the hydroxyl radical (Scheme 8) (Danilewicz 2003, Elias and Waterhouse 2010). The $\mathrm{HO} \bullet / \mathrm{H}_{2} \mathrm{O}$ couple has a large positive reduction potential (Scheme 6), and consequently it is a powerful oxidant. It reacts at diffusion-controlled rates,

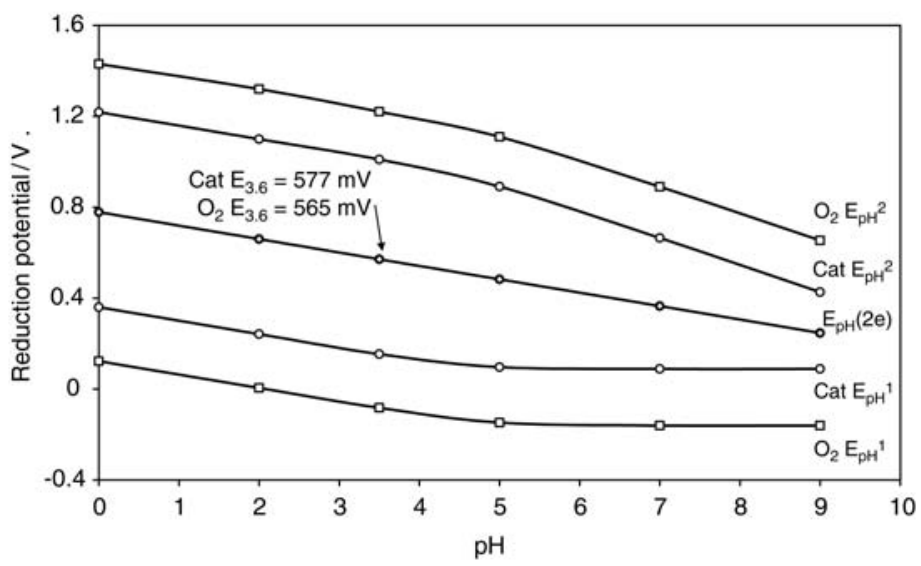

Figure $4 \mathrm{pH}$ dependence of first $\left(\mathrm{E}_{\mathrm{pH}}{ }^{1}\right)$, second $\left(\mathrm{E}_{\mathrm{pH}}{ }^{2}\right)$, and two-electron $\left(\mathrm{E}_{\mathrm{pH}}(2 \mathrm{e})\right)$ reduction potentials of the $(+)$-catechin (Cat) and $\mathrm{O}_{2} / \mathrm{H}_{2} \mathrm{O}_{2}\left(\mathrm{O}_{2}\right)$ redox systems. Values for the two-electron reduction potentials are essentially the same and the resulting curves are superimposed. 
meaning it attacks the first potential reductant it encounters, which in wine is likely to be ethanol. It abstracts an $\alpha$-hydrogen atom to produce the hydroxyethyl radical. The radical is highly reducing, with $\mathrm{E}_{3.6}{ }^{1}=-1.18 \mathrm{~V}$ for the acetaldehyde/hydroxyethyl radical couple. However, mechanistic studies suggest that it reacts rapidly with oxygen to produce a hydroxyethylperoxide radical, which is proposed to eliminate a hydroperoxyl radical to form acetaldehyde (Scheme 8). The hydroperoxyl radical may then react as shown in Scheme 7, while polyphenols return $\mathrm{Fe}$ (III) to the ferrous state to continue the reaction (Elias and Waterhouse 2010).

Taking the two-electron reduction potential $\left(\mathrm{E}_{7}\right)$ for ethanol as $-0.19 \mathrm{~V}$ (Clark 1960) and $\mathrm{E}_{7}{ }^{1}$ as $-1.38 \mathrm{~V}$ (Koppenol and Butler 1985), $\mathrm{E}_{7}^{2}$ will be $1.0 \mathrm{~V}$, giving the values shown in Scheme 9 at pH 3.6. The abstraction of the ethanol $\alpha$-hydrogen atom by the hydroxyl radical is thermodynamically highly favored with $\Delta \mathrm{E}_{3.6}=1.33 \mathrm{~V}$ (Scheme 9). This reaction is rapid, but it should be appreciated that thermodynamically favored reactions need not necessarily occur, as is the case with the reaction of ethanol with oxygen. The reaction does not pro-

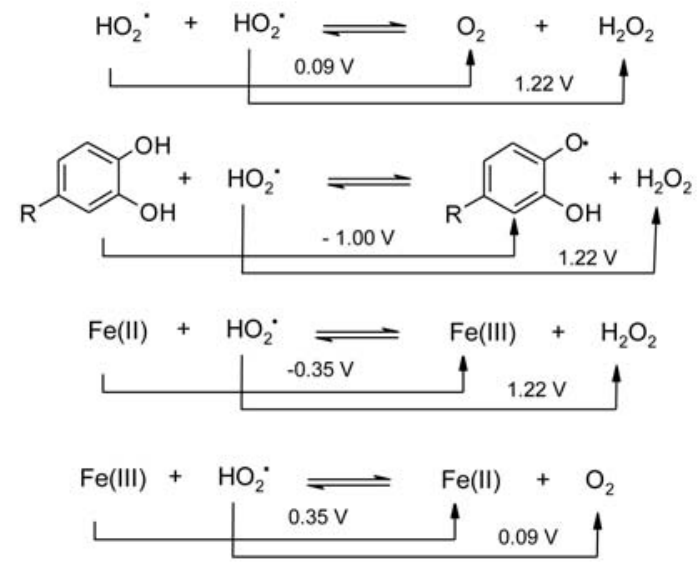

Scheme 7 Possible reactions of the hydroperoxyl radical at $\mathrm{pH} 3.6$ by disproportionation and reaction with (+)- catechin, $\mathrm{Fe}(\mathrm{II})$, and $\mathrm{Fe}(\mathrm{III})$.

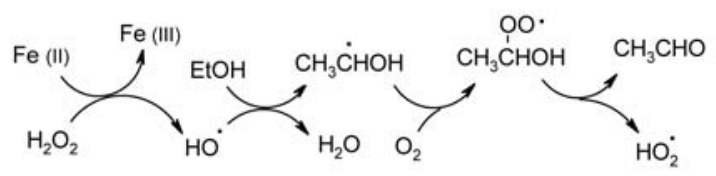

Scheme 8 Oxidation of ethanol by the Fenton reaction.

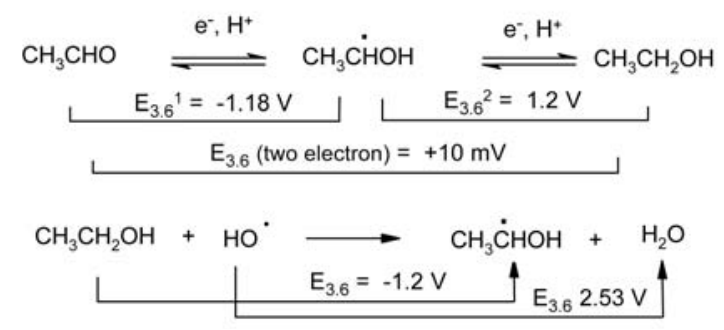

Scheme 9 Reduction potentials for the acetaldehyde/ethanol redox couple and first step in the oxidation of ethanol. ceed spontaneously until a mechanistic path, such as provided by polyphenols, becomes available.

The formation of the hydroxyethyl radical has been confirmed in wine by oxidizing it in the presence of the spin trap $\alpha$-(4-pyridyl-1-oxide)- $N$-tert-butylnitrone (POBN). Electron spin resonance spectroscopy produced a six-line spectrum ascribed to the spin adduct, which was identical to that observed when hydrogen peroxide and Fe(II) were added to the wine and a model wine system. Using a high concentration of POBN to compete with the ethanol, a spectrum ascribed to the POBN-HO• spin adduct was obtained (Elias et al. 2009).

The oxidation of sulfite by oxygen is also metal-catalyzed and involves a radical-chain reaction. The process is initiated by the oxidation of sulfite by $\mathrm{Fe}(\mathrm{III})$ to produce sulfite radicals $\left(\mathrm{SO}_{3}^{\bullet}\right)$ (Scheme 10$)$. This initial radical reacts rapidly with oxygen to produce the peroxomonosulfate radical $\left(\mathrm{SO}_{5}{ }^{-}\right)$, which is a stronger oxidant $\left(\mathrm{E}_{3.6}=1.17 \mathrm{~V}\right.$ versus 0.95 V) capable of oxidizing polyphenols (Scheme 11) (Das et al. 1999). It is proposed that by intercepting this radical, polyphenols prevent radical-chain propagation and so prevent sulfite autoxidation in wine (Danilewicz 2007, Danilewicz and Wallbridge 2010). In the absence of polyphenols the sulfate radical is produced, which as a comparable oxidant to the hydroxy radical is also capable of oxidizing ethanol (Danilewicz 2007, Elias et al. 2009).

It is interesting to consider that sulfite and polyphenols, which are described as antioxidants, both activate oxygen to oxidize ethanol. Consequently, although polyphenols and sulfite alone can promote oxidation, when combined, perhaps by great good fortune, they act as antioxidants in wine. Polyphenols scavenge harmful $\mathrm{SO}_{2}$-derived radicals and sulfite reacts with hydrogen peroxide, allowing oxygen to be removed harmlessly. This may be the origin of the unnecessary confusion that is caused by referring to these substances as prooxidant or antioxidant under different conditions. Polyphenols are antioxidant in the sense that they will intercept damaging free radicals in vivo, for example, to produce less reactive semiquinones. However, quinones are eventually produced,

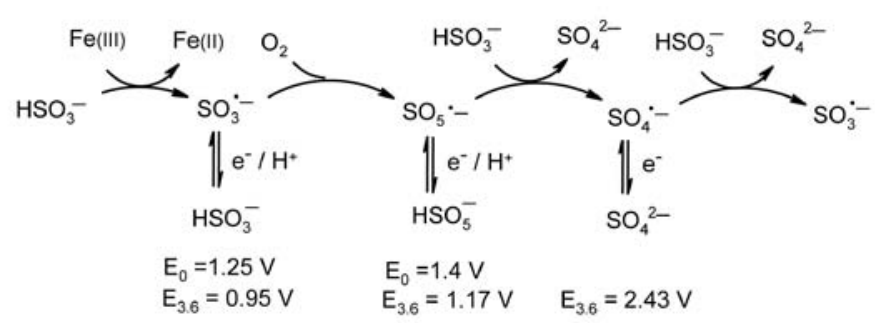

Scheme 10 Radical-chain reaction involved in sulfite autoxidation.

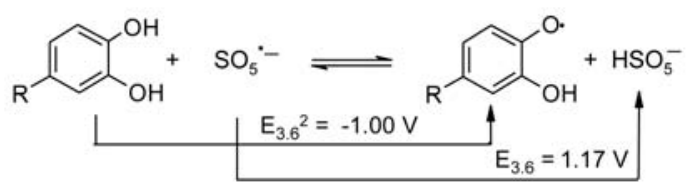

Scheme 11 Interception of the peroxomonosulfate radical by (+)-catechin. 
which are potentially harmful as they can react with amines and thiols in proteins at physiological $\mathrm{pH}$ and so disrupt vital biological processes (Bolton et al. 2000). By reacting rapidly with quinones in wine, sulfite has the additional greatly beneficial property of preventing damaging condensation reactions leading to browning and loss of aroma constituents.

\section{Conclusions}

The reduction potential of wines has been assumed to indicate their redox state, although without a satisfactory explanation as to how they might be generated. For a reduction potential to indicate the state of oxidation of a wine, it should reflect the extent of oxidation of polyphenols, which are its most readily oxidized constituents. Polyphenols and their respective quinones should, therefore, be at equilibrium and should contribute to the overall potential according to their relative concentrations, which would depend on level of oxidation. However, there is clear evidence that polyphenols do not contribute to reduction potential and, in any case, quinones are too unstable to be present in significant amounts. It is proposed that these potentials are generated by the oxidation of ethanol at platinum electrodes and dependent largely on oxygen concentration at the time of measurement. They are, therefore, of little value for determining the so-called redox state of wines, a state which also needs to be more clearly defined. In contrast, cyclic voltammetry is proving very useful to determine the reduction potential of wine constituents in winelike conditions and to estimate the concentration of the most readily oxidized polyphenols. Consideration of reduction potentials of redox couples of likely reactants offers useful insights into possible mechanisms involved in wine oxidation. The reaction of polyphenols with oxygen is mediated by iron and copper and accelerated by sulfite, which then reduces the quinones that are produced back to the polyphenol, so preventing their depletion. Sulfite does not react with oxygen directly. It accelerates the rate of oxygen uptake, and hence its removal, but then exerts its antioxidant action by regenerating polyphenols as well as intercepting hydrogen peroxide, so preventing ethanol oxidation. The rate of polyphenol oxidation is determined not only by iron and copper concentrations but also by substances that react with quinones, which is influenced by $\mathrm{pH}$.

\section{Literature Cited}

Ball, E.G., and T.T. Chen. 1933. Studies on oxidation-reduction. XX. Epinephrine and related compounds. J. Biol. Chem. 102:691-719.

Bard, A.J., and L.R. Faulkner. 2001. Electrochemical Methods. Fundamentals and Application. Wiley \& Sons, New York.

Barril, C., A.C. Clark, P.D. Prenzler, P. Karuso, and G.R. Scollary. 2009. Formation of pigment precursor (+)-1"-methylene-6"-hydroxy$2 \mathrm{H}$ - furan-5"-one-catechin isomers from $(+)$-catechin and a degradation product of ascorbic acid in a model wine system. J. Agric. Food Chem. 57:9539-9546.

Bolton, J.L., M.A. Trush, T.M. Penning, G. Dryhurst, and T.J. Monks. 2000. Role of quinones in toxicology. Chem. Res. Toxicol. 13:135-160.

Bradshaw, M.P., C. Barril, A.C. Clark, P.D. Prenzler, and G.R. Scollary. 2011. Ascorbic acid: A review of its chemistry and reactivity in relation to a wine environment. Crit. Rev. Food Sci. Nutr. 51(6):479-498.
Buettner, G.R. 1993. The pecking order of free radicals and antioxidants: Lipid peroxidation, $\alpha$-tocopherol and ascorbate. Arch. Biochem. Biophys. 300:535-543.

Clark, W.M. 1960. Oxidation-Reduction Potentials of Organic Systems. Williams and Wilkins, Baltimore.

Compton, R.G., and G.H. Sanders. 1996. Electrode Potentials. Oxford University Press, New York.

Conant, J.B., and L.F. Fieser. 1924. Reduction potentials of quinones. II. The potentials of certain derivatives of benzoquinone, naphthoquinone and antraquinone. J. Am. Chem. Soc. 46:1858-1881.

Danilewicz, J.C. 2003. Review of reaction mechanisms of oxygen and proposed intermediate reduction products in wine: Central role of iron and copper. Am. J. Enol. Vitic. 54:73-85.

Danilewicz, J.C. 2007. Interaction of sulfur dioxide, polyphenols, and oxygen in a wine-model system: Central role of iron and copper. Am. J. Enol. Vitic. 58:53-60.

Danilewicz, J.C. 2011. Mechanism of autoxidation of polyphenols and participation of sulfite in wine: Key role of iron. Am. J. Enol. Vitic. 62:319-328

Danilewicz, J.C., and P.J. Wallbridge. 2010. Further studies on the mechanism of interaction of polyphenols, oxygen, and sulfite in wine. Am. J. Enol. Vitic. 61:166-175.

Das, T.N., R.E. Huie, and P. Neta. 1999. Reduction potentials of $\mathrm{SO}_{3}{ }^{--}, \mathrm{SO}_{5}{ }^{--}$and $\mathrm{S}_{4} \mathrm{O}_{6}{ }^{\cdot 3-}$ radicals in aqueous solution. J. Phys. Chem. 103:3581-3588.

Davies, R. 1976. The synthesis and isolation of caffeoquinone and caffeoquinone methyl ester. Tetrahedron Lett. 17:313-314.

Dikanović-Lučan, Z., and A. Palić. 1992. Redox-potential of wines from a Croatian market. Z. Lebensm.-Unters.-Forsch. 195:133-136.

Elias, R.J., and A.L. Waterhouse. 2010. Controlling the Fenton reaction in wine. J. Agric. Food Chem. 58:1699-1707.

Elias, R.J., M.L. Andersen, L.F. Skibsted, and A.L. Waterhouse. 2009. Key factors affecting radical formation in wine studied by spin trapping and EPR spectroscopy. Am. J. Enol. Vitic. 60:471-476.

Green, R.W., and G.M. Parkins. 1961. Complexes of iron with D-tartaric and meso-tartaric acids. J. Phys. Chem. 65:1658-1659.

Horner, L., and E. Geyer. 1965. Redoxpotentiale von benzcatechinderivaten. Chem. Ber. 98:2016-2045.

Joslyn, M.A. 1949. California wines. Oxidation- reduction potentials at various stages of production and aging. Ind. Eng. Chem. 41:587-592.

Jovanovic, S.V., S. Steenken, Y. Hara, and M.G. Simic. 1996. Reduction potentials of flavonoid and model phenoxyl radicals. Which ring in flavonoids is responsible for antioxidant activity? J. Chem. Soc., Perkin Trans. 2 2497-2504.

Kilmartin, P.A. 2001. Electrochemical detection of natural antioxidants: Principles and protocols. Antiox. Redox Signal. 3:941-955.

Kilmartin, P.A. 2010. Understanding and controlling non-enzymatic wine oxidation. In Understanding and Managing Wine Quality and Safety. A.G. Reynolds (ed.), pp. 432-458. Woodhead Publishing, Cambridge, UK.

Kilmartin, P.A., and H. Zou. 2001. The effect of electrode material on the measured redox potential of red and white wines. Electroanalysis 13:1347-1350.

Kilmartin, P.A., H. Zou, and A.L. Waterhouse. 2001. A cyclic voltammetry method suitable for characterizing antioxidant properties of wine and wine phenolics. J. Agric. Food Chem. 49:1957-1965.

Kilmartin, P.A., H. Zou, and A.L. Waterhouse. 2002. Correlation of wine phenolic composition versus cyclic voltammetry response. Am. J. Enol. Vitic. 53:294-302.

Koppenol, W.H., and J. Butler. 1985. Energetics of interconversion reactions of oxyradicals. Adv. Free Radical Biol. Med. 1:91-131. 
Makhotkina, O., and P.A. Kilmartin. 2009. Uncovering the influence of antioxidants on polyphenol oxidation in wines using an electrochemical method: Cyclic voltammetry. J. Electroanal. Chem. 633:165-174.

Makhotkina, O., and P.A. Kilmartin. 2010. The use of cyclic voltammetry for wine analysis: Determination of polyphenols and free sulfur dioxide. Anal. Chim. Acta 668:155-165.

Martins, R.C., R. Oliveira, F. Bento, D. Geraldo, V.V. Lopes, P. Guedes de Pinho, C.M. Oliveira, and A.C. Silva Ferreira. 2008. Oxidation management of white wine using cyclic voltammetry and multivariate process monitoring. J. Agric. Food Chem. 56:12092-12098.

Meisel, D., and G. Czapski. 1975. One-electron transfer equilibria and redox potentials of radicals studied by pulse radiolysis. J. Phys. Chem. 79:1503-1509.

Nematollahi, D., and R.A. Rahchamani. 2002. Electro-oxidation of catechols in the presence of benzenesulfinic acid. Application to electro-organic synthesis of new sulfone derivatives. J. Electroanal. Chem. 520:145-149.

Oliveira, C.M., A.C. Silva Ferreira, P. Guedes de Pinho, and T.A. Hogg. 2002. Development of a potentiometric method to measure the resistance to oxidation of white wines and the antioxidant power of their constituents. J. Agric. Food Chem. 50:2121-2124.

Ribéreau-Gayon, P., Y. Glories, A. Maujean, and D. Dubourdieu. 2000. Handbook of Enology. Vol. 2. The Chemistry of Wine Stabilization and Treatments. Wiley \& Sons, New York.

Richard-Forget, F.C., M.A. Rouet-Mayer, P.M. Goupy, J. Philippon, and J.J. Nicolas. 1992. Oxidation of chlorogenic acid, catechins, and 4-methylcatechol in model solutions by apple polyphenol oxidase. J. Agric. Food Chem. 40:2114-2122.

Rodrigues, A., A.C. Siva Ferreira, P. Guedes de Pinho, F. Bento, and D. Geraldo. 2007. Resistance to oxidation of white wines assessed by voltammetric means. J. Agric. Food Chem. 55:10557-10562.

Timberlake, C.F. 1964. Iron-tartrate complexes. J. Chem. Soc. 1229 1240.

Tomlinson, J.W., and P.A. Kilmartin. 1997. Measurement of the reduction potential of wine. J. Appl. Electrochem. 27:1125-1134.

Vivas, N., F. Zamora, and Y. Glories. 1992. Étude des phénomenes d'oxydoréduction dans les vins. Mise au point d'une méthode rapide de mesure du potential d' oxydoréduction. J. Int. Sci. Vigne Vin 26:271-285.

Vivas, N., F. Zamora, and Y. Glories. 1993. Incidence de certains facteurs sur la consommation de 1'oxygène et sur le potentiel d'oxydoréduction dans les vins. J. Int. Sci. Vigne Vin 27:23-34.

Wildenradt, H.L., and V.L. Singleton. 1974. The production of aldehydes as a result of oxidation of polyphenolic compounds and its relation to wine aging. Am. J. Enol. Vitic. 25:119-126.

Wood, P.M. 1988. The potential diagram for oxygen at $\mathrm{pH}$ 7. Biochem. J. 253:287-289.

Yokoi, H., T. Mitani, Y. Mori, and S. Kawata. 1994. Complex formation between iron(III) and tartaric and citric acids in a wide $\mathrm{pH}$ range 1 to 13 as studied by magnetic susceptibility measurements. Chem. Lett. 23:281-284. 